\title{
Quality of Life of Family Caregiver of Cancer Patient: A Literatur Review
}

\author{
Nur Maziyya, Laili Rahayuwati, Ahmad Yamin \\ Faculty of Nursing Unpad \\ Email: nurmaziyya@gmail.com
}

\begin{abstract}
Background: Cancer is one of chronic diseases that require long-term care. Family as the closest one who lives with the cancer patient takes a leading role in providing care. It causes some impacts that possible happen to family caregiver (FCs) such as feeling burden and decreasing quality of life (QoL). Purpose: This literature review was conducted to describe findings from studies concerning QoL of FCs of cancer patients. Methods: This review used scoping review methods. Electronic literature searching was conducted using databases: Proquest, PubMed, Google scholar and Science Direct using keywords quality of life, family caregiver and cancer patient/terminal patient/terminally ill patient. Inclusion criteria were: research papers, focus on caregiver of cancer patient, peer-reviewed, and published between 2008-2018. Exclusion criteria was nonEnglish papers and papers that discuss other than caregiver of cancer patients. There were a total of 45 papers retrieved; however, only 13 papers met the inclusion and exclusion criteria. Analysis was conducted using content analyses. Findings: Research about QoL of FCs of cancer patient have been done in some countries and used some different methodes. They showed that the primary FCs of cancer patient were spouses and had low QoL. Factors that associated with FCs' QoL such as patients' age and condition, spousal relationship, FCs' religiousness, emotional distress, carigiving burden, lack of social support and satisfaction with care. Conclusions And Recommendations: FCs of cancer patients had low quality of life and caused by many factors. Further studies required to determine other factors from patients, FCs and environment that influence the FCs' QoL.
\end{abstract}

Keywords: Cancer patient, family caregiver, quality of life. 
Nur Maziyya: Quality of Life of Family Caregiver of Cancer Patient: A Literature Review

\section{Introduction}

Every family around the world is almost familiar and exposed to cancer in which cancer is one of the main causes of six deaths worldwide (WHO, 2018). Cancer occurs when cells in the body grow uncontrolled and disrupt the body to function properly (American Cancer Society, 2015). Cancer is a chronic disease that requires long-term care. The current trend of cancer care is not only hospital treatment but an outpatient that allows care to be done at home. The family as the nearest person will take a leading role in the provision of care. (Given et al., 2001; Teschendorf et al., 2007 in Rha, Park, Song, Lee, \& Lee, 2015).

Family caregiver is a term that refers to someone who cares for a relative or a loved one (Guerriere, Zagorski, \& Coyte, 2010). In the case of cancer, family caregiver has many roles starting from the time the patient is diagnosed, during treatment either in hospital or at home until end of life treatment (National Cancer Institute, 2017). In addition, the family caregiver also has an obligation to provide various kinds of assistance such as disease monitoring and treatment, sign and symptom management, medical administration, emotional support, personal and instrumental treatment and economic assistance (Given et al., 2001; Yun et al., 2005 in Rha et al., 2015). The number of responsibilities that must be done causes the family caregiver to experience various problems and difficulties that can cause stress and may affect their quality of life.

Family caregiver in cancer patients tends to be susceptible to decreased quality of life. Mahendran and Lim (2015) mentioned that the quality of life in caregiver family of cancer patients has a low quality of life. The decline can occur because cancer is a disease that is identical with the threat of death (Weitzner et al., 1999). In addition, the caregiving and maintenance processes perceived by families tend to affect their quality of life (Tang et al., 2008 in Rha et al., 2015). Factors affecting quality of life need to be known to prevent the decline. In addition, the quality of life in caregiver family is important to note because it is feared will affect the quality of care given to cancer patients.

Research on quality of life of family caregiver of cancer patients has been done in several countries. There were also researches on the factors that influence it. Therefore, this literature study was conducted to determine the quality of life of family caregiver of cancer patients and factors that have been proven affected the quality of life.

\section{Research Method}

The literature study was conducted by reviewing published research articles. The search method used several electronic databases such as Google Scholar, Proquest, PubMed, SpringerLink and Science Direct. Articles obtained through keywords quality of life, family caregiver, cancer patient or terminally ill patient or terminal patient. A total of 10,417 papers were obtained. The inclusion criteria in this literature study were quantitative and qualitative research papers in English-language, fulltext, peer reviewed, published between 2008-2018. Exclusion criteria include only abstract papers, nonresearch papers, paper's content was not relevant to the purpose of writing and articles that did not have the structure of a good article (Abstract, Instoduction, Methods, Results, Discussions, Implications, and References).

After sorting, 14 articles met the inclusion criteria and 21 articles entered into the exclusion criteria. Articles that meet the criteria were read intensively then be analyzed based on content analyses.

\section{Research Results}

Table 1 Result of Literature Search

\begin{tabular}{lccc}
\hline \multicolumn{1}{c}{ Databases } & $\begin{array}{c}\text { Number of articles } \\
\text { according to keywords }\end{array}$ & $\begin{array}{c}\text { Number of articles } \\
\text { obtained }\end{array}$ & $\begin{array}{c}\text { Number of articles } \\
\text { match the inclusion } \\
\text { criteria }\end{array}$ \\
\hline Google Scholar & 2100 & 13 & 4 \\
Proquest & 2980 & 15 & 2 \\
\hline
\end{tabular}


Nur Maziyya: Quality of Life of Family Caregiver of Cancer Patient: A Literature Review

\begin{tabular}{lccc}
\hline PubMed & 2730 & 4 & 3 \\
SpringerLink & 73 & 4 & 1 \\
Science Direct & 2534 & 9 & 3 \\
Total & $\mathbf{1 0 , 4 1 7}$ & $\mathbf{4 5}$ & $\mathbf{1 3}$ \\
\hline
\end{tabular}

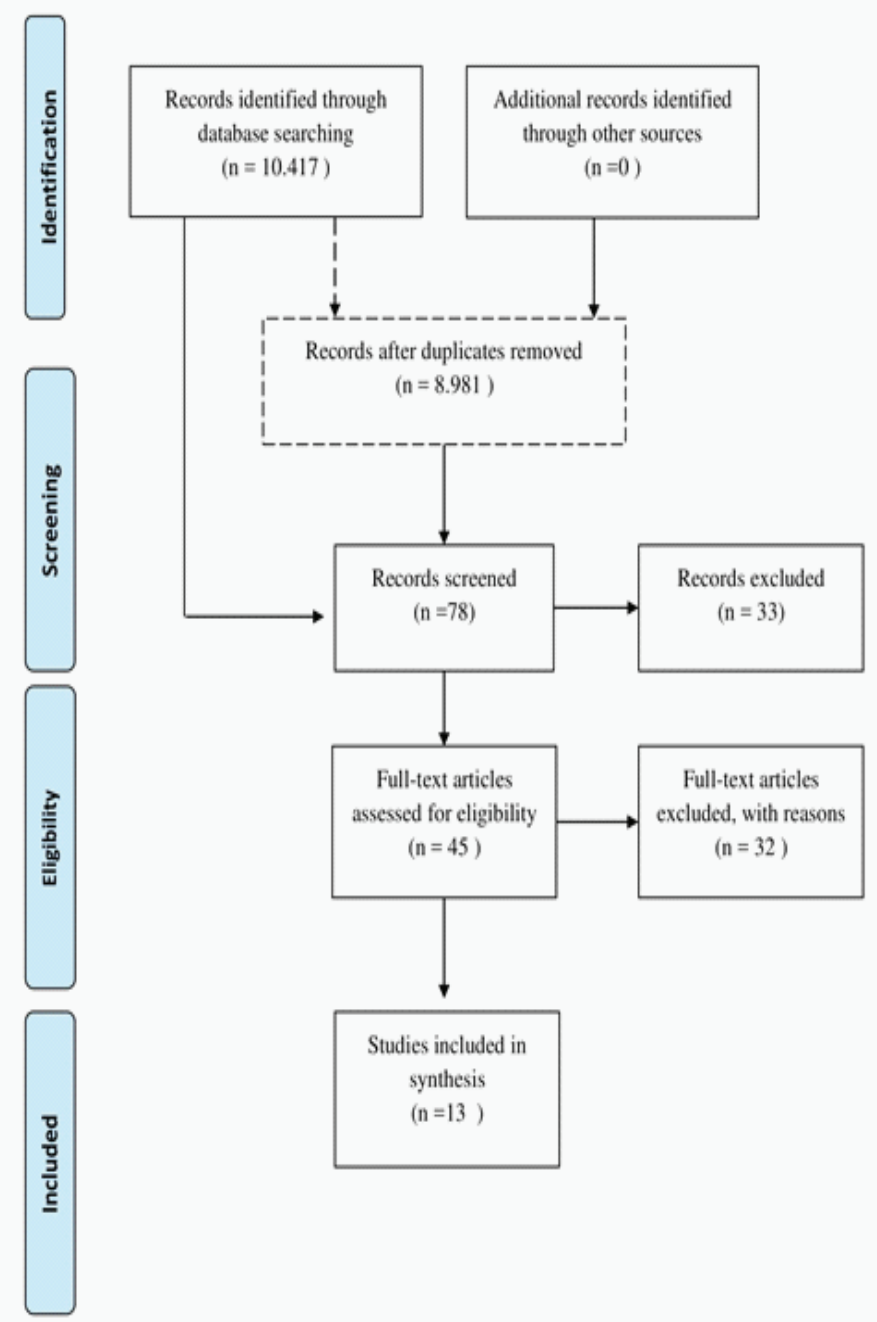


Nur Maziyya: Quality of Life of Family Caregiver of Cancer Patient: A Literature Review

\section{Study Characteristics}

After screening the papers, there were 14 papers that met the inclusion and exclusion criteria for analysis of content analysis. It was known that research about family caregiver's quality of life of cancer patient has been done in some countries such as Korea, Japan, China, Sweden, Greece, Italy, California, Canada, Colombia, and Taiwan (Table 2). Design of study were epidemiological study and quantitative studies. Study methodes that used were quantitative cross-sectional, descriptive, prospective quasi-experimental trial, cluster-randomized controlled trial, prospective longitudinal, paired cohort (Table $3)$.

\section{Family Caregivers' Characteristics}

Result obtained from many researches showed that charateristics of family caregivers were mostly female (more than 60\%), in aged over 50 years old and had relationship with patients as spouses and/ or parents.

\section{Quality of life of Family Caregivers}

Result obtained from many researches showed that family caregivers (FCs) of cancer patients mostly had quality of life (QoL) decreased, felt burdened with care to patients, felt depression and psychological distress.

\section{Factors that affect the quality of life of Family caregivers}

Factors that affect the quality of life caregivers family of cancer patients can be divided into 3 categories namely patient factors, family caregivers factors and also environmental factors. Patient factors that affect quality of life include age and patient condition. Family caregivers factors, among others, the relationship that is owned with the patient, the level of education and religious and emotional distress. While environmental factors consist of perceived maintenance burden, lack of social support and also the level of satisfaction on health services.

Table 2 Distribution of Research Sites

\begin{tabular}{|c|c|}
\hline Place of study & Number of articles \\
\hline Korea & 4 \\
\hline Japan & 1 \\
\hline China & 2 \\
\hline Sweden & 1 \\
\hline Greece & 1 \\
\hline California & 1 \\
\hline Canada & 1 \\
\hline Colombia & 1 \\
\hline Taiwan & 1 \\
\hline Total & 13 \\
\hline
\end{tabular}

Table 3 Research Design

\begin{tabular}{lc}
\hline \multicolumn{1}{c}{ Research design } & Number of articles \\
\hline Epidemiological Study & 1 \\
Quantitative cross-sectional & 5 \\
Descriptive & 4 \\
Prospective quasi-experimental trial & 1 \\
Cluster-randomized controlled trial & 1 \\
Prospective longitudinal & 1 \\
Total & $\mathbf{1 3}$ \\
\hline
\end{tabular}


Nur Maziyya: Quality of Life of Family Caregiver of Cancer Patient: A Literature Review

Table 4. Article Summary

\begin{tabular}{|c|c|c|c|c|c|}
\hline $\begin{array}{c}\text { Author \& } \\
\text { year }\end{array}$ & $\begin{array}{c}\text { Place of } \\
\text { Study }\end{array}$ & Study design & Sample & Variable & Instrument \\
\hline $\begin{array}{l}\text { Song et al., } \\
\text { (2011) }\end{array}$ & Korea & $\begin{array}{l}\text { Quantitative } \\
\text { (cross- } \\
\text { sectional) }\end{array}$ & $\begin{array}{l}160 \text { family } \\
\text { caregivers } \\
\text { (FCs) of } \\
\text { inpatient } \\
\text { palliative care }\end{array}$ & $\begin{array}{c}\text { FCs' } \\
\text { Quality of } \\
\text { life and } \\
\text { mental } \\
\text { health }\end{array}$ & $\begin{array}{l}\text { EQ-5D and } \\
\text { Caregiver } \\
\text { Reaction } \\
\text { Assessment } \\
\text { (CRA) }\end{array}$ \\
\hline
\end{tabular}

Lee et al., Kore

Quantitative
(cross-
sectional)
178 patient-
FCs pairs
from six
tertiary
hospital
hospice
palliative care
units in South
Korea

Patient's
and FCs
Quality of
life

EORTC

QLQ-C15PAL

Korean

Version of

Caregiver

Quality Of

Life Index-

Cancer

(CQOLC-K)
Finding

Health related QoL (HRQoL) in

caregiver of terminal cancer patient was significantly lower than the controls.

They experienced depression more frequent than controls did. Factors that influence on HR-QoL were from demographics factors and caregiver burden. Demographics factors that influence on HR-QOL were religion and education level which had positive correlation. Caregiver burden had a negative influence on the HR-QoL such as "impact on health", "financial problems" and "lack of family support". Factors that influence of mental health were age (the older caregiver felt less stress than younger one, but more frequent of thougt of suicidal), lack of family support (increased of suicidal thought). Financial problems increased of felt depression and the impact of health increased family caregiver stress.

Most FCs were female (74.6\%) and patient's spouse $(41.1 \%)$. Factors that impact FCs' QoL were patient factor, caregiver factors and environmental factors. From patient factors, age was the only factors that influence on FCs' QoL (family caregiver of younger patient felt more burden than older patient). From caregiver factors such as age, marital status, religiousness, relationship to the patient and emotional distress impact on FCs' QoL (emotional distress was the strongest one). From environmental factors that influence on FCs' QoL were objective burden of care, social support level, family function, satisfaction with care, and monthly household income.

The median of caregiver's age was $50,73,3 \%$ caregiver were female. The QoL of FCs did not have association with quality of life of patient. Factors that impact of lower QoL of FCs were emotional distress, lack of social support and FCs who professed a religion. 
Nur Maziyya: Quality of Life of Family Caregiver of Cancer Patient: A Literature Review

\begin{tabular}{|c|c|c|c|c|c|}
\hline $\begin{array}{l}\text { Ito \& } \\
\text { Tadaka } \\
(2017)\end{array}$ & Japan & $\begin{array}{c}\text { An } \\
\text { epidemio- } \\
\text { logical study }\end{array}$ & $262 \mathrm{FCs}$ & $\begin{array}{c}\text { FCs' } \\
\text { Quality of } \\
\text { life }\end{array}$ & $\begin{array}{c}\text { Japanese } \\
\text { Version of } \\
\text { Caregiver } \\
\text { Quality Of } \\
\text { Life Index- } \\
\text { Cancer } \\
\text { (CQOLC-J) }\end{array}$ \\
\hline
\end{tabular}

Yu et al.,
$(2017)$

Sjolander, Rolander, Järhult, Mårtensson, \& Ahlstrom (2012)

Rha, Park, Song, Lee, \& Lee (2015)

$\begin{array}{ccc}\text { China } & \begin{array}{c}\text { Quantitative } \\ \text { (cross- }\end{array} & \text { 309 FCs for } \\ \text { sectional) } & \text { leukemia } \\ & \text { patients } \\ & \text { recruited } \\ & \text { from three } \\ & \text { hospitals in } \\ & \text { Heilongjiang } \\ & \text { province. }\end{array}$

\section{FC's \\ Quality of life}

Chinese version of WHOQOLBREF.
FCs'

Health

Related

Quality

of Life

(HRQoL)

quantitative

members
Short Form

36 Health

Survey (SF36)

EuroQol

(EQ-5D)
212 FCs

of cancer patients
FCs burden
FCs
Quality of life
The Korean versions of Zarit Burden Interview WHOQOLBREF
There only 74 questionaires that could be analyzed. Demographics data from caregiver was $79,9 \%$ family caregiver was female with mean age was 63,6 years. Factors that were associated with FCs' QoL were depression, family caregiver's self efficacy, presence/ absence of subcaregiver and satisfaction with homecare services.

Most of FCs were women (54,7\%), parents $(44,0 \%)$ or spouses $(36,9)$ of the patients. They had low scores of QoL in all four domains (physical, psychological, social and environment). Factors that had a strong influence of all domains of QoL was social support, then family function which influence three domains of QoL (psychological, social and environmental domains). Other factors that caused lower QoL were older FCs, had highly education, no religious belief, suffered a higher emotional distress, cared for younger patients and had no insurance coverage.

$72 \%$ family members were women and patients' partner as a primary caregiver. Family members of cancer patient had poor health related quality of life (HRQoL) after being assesed using SF-36 and EQ-5D VAS for 1 year.

Risk factors that influence of family members' HRQOL were age. The older caused physical domain decreased and younger caused poorer mental domain of HRQOL.

$79,2 \%$ caregivers were female and $48,6 \%$ were spouses. Most all of FCs of cancer patients experienced a moderete level of cargiving burden and one-quarter of them experience a high caregiving burden. Factor that had a high influence on high caregiving burden was functional deterarioration of patient. FCs had a moderete QoL. Factors that caused a lower QoL were caregivers's educational level and hospitalized patients. Caregiving burden had a negative relation to QoL of FCs of cancer patient. 
Nur Maziyya: Quality of Life of Family Caregiver of Cancer Patient: A Literature Review

\begin{tabular}{|c|c|c|c|c|c|c|}
\hline $\begin{array}{l}\text { Govina et } \\
\text { al. } \\
(2015)\end{array}$ & $\begin{array}{l}\text { Athens, } \\
\text { Greece }\end{array}$ & $\begin{array}{l}\text { Quantitative } \\
\text { (cross- } \\
\text { sectional) }\end{array}$ & $\begin{array}{l}100 \text { pairs of } \\
\text { patients and } \\
\text { FCs } \\
\text { at one } \\
\text { radiotherapy } \\
\text { centre. }\end{array}$ & $\begin{array}{l}\text { FCs' } \\
\text { burden }\end{array}$ & $\begin{array}{c}\text { Bakas } \\
\text { Caregiving } \\
\text { Out-comes } \\
\text { Scale-Greek } \\
\text { version } \\
\text { (Greek } \\
\text { BCOS) } \\
\text { Oberst } \\
\text { Caregiving } \\
\text { Burden Scale } \\
\text { (OCBC) } \\
\text { Hospital } \\
\text { Anxiety and } \\
\text { Depresion } \\
\text { Scale-Greek } \\
\text { version } \\
\text { (G-HADS). }\end{array}$ & $\begin{array}{l}76 \% \text { FCs were female and } 59 \% \text { were } \\
\text { spouses. Patient and caregiver variables } \\
\text { had relation to caregiving burden. } \\
\text { Patient variable was patients' past } \\
\text { surgery and caregivers' variables were } \\
\text { caregivers' depressed mood, perceived } \\
\text { difficulty in caring, family status, } \\
\text { employment status. FCs of cancer } \\
\text { patient in Greek experienced greater } \\
\text { deppresive mood and felt difficult in } \\
\text { caregiving task those caused by married } \\
\text { status not employed and caring patients } \\
\text { that had not undergone surgery. }\end{array}$ \\
\hline$\underset{(2016}{\text { Kim et al., }}$ & California & $\begin{array}{l}\text { Prospective, } \\
\text { quasi- } \\
\text { experimental } \\
\text { trial }\end{array}$ & $\begin{array}{l}41 \text { pairs of } \\
\text { patients and } \\
\text { FCs }\end{array}$ & $\begin{array}{c}\text { Patient's } \\
\text { Quality of } \\
\text { life } \\
\text { FCs' } \\
\text { Quality } \\
\text { of life \& }\end{array}$ & $\begin{array}{c}\text { Functional } \\
\text { Assessment } \\
\text { of Cancer } \\
\text { Therapy- } \\
\text { Lung } \\
\text { FCs version } \\
\text { of the City of } \\
\text { Hope QoL } \\
\text { Distress } \\
\text { Thermometer }\end{array}$ & $\begin{array}{l}\text { Patients and FCs had highest } \\
\text { psychological distress levels were } \\
\text { highest before surgery }(3.8 / 10 \text { and } \\
5.1 / 10) \text {. Patients'distress levels } \\
\text { decreased among at six }(2.9 / 10) \text { and } 12 \\
\text { weeks }(2.2 / 10, \mathrm{p}=0.001) \text { after surgery, } \\
\text { but FCs' were elevated }(4.2 / 10 \text { and } \\
4.4 / 10, \mathrm{p}=0.157) \text {. With a usual care, } \\
\text { patients' QoL was increase especially } \\
\text { in physical and funtional domain. But, } \\
\text { there was no significant benefit for FCs } \\
\text { in any domain. It could be concluted that } \\
\text { FCs of lung cancer patients experience a } \\
\text { hard psychological distress. }\end{array}$ \\
\hline $\begin{array}{l}\text { Lu et al., } \\
(2010)\end{array}$ & China & $\begin{array}{l}\text { Quantitative } \\
\text { (cross- } \\
\text { sectional) }\end{array}$ & $\begin{array}{l}358 \text { FCs of } \\
\text { cancer patient }\end{array}$ & $\begin{array}{c}\text { FCs' } \\
\text { Quality of } \\
\text { life }\end{array}$ & $\begin{array}{l}\text { QOL Family } \\
\text { Version } \\
\text { (offered by } \\
\text { the American } \\
\text { National } \\
\text { Medical } \\
\text { Center and } \\
\text { the Beckman } \\
\text { Research } \\
\text { Institute }\end{array}$ & $\begin{array}{l}\text { The average of FCs' QoL was 5.26. } \\
\text { Domains that disrupted seriously were } \\
\text { Psychological well-being and social } \\
\text { concerns of FCs. Factors that associated } \\
\text { with FCs QoL were spousal relationship, } \\
\text { patients' ADL and the patient' condition } \\
\text { (chronic illness). The strongest } \\
\text { association that affected on FCs' QoL } \\
\text { was spousal relationship. }\end{array}$ \\
\hline $\begin{array}{l}\text { Wadhwa et } \\
\text { al., (2013) }\end{array}$ & Canada & $\begin{array}{l}\text { Cluster- } \\
\text { randomized } \\
\text { trial }\end{array}$ & $\begin{array}{l}191 \text { pairs of } \\
\text { patients and } \\
\text { FCs }\end{array}$ & $\begin{array}{c}\text { FCs' } \\
\text { Quality } \\
\text { of life \& } \\
\text { health } \\
\text { functioning }\end{array}$ & $\begin{array}{c}\text { Caregiver } \\
\text { Quality of } \\
\text { Life Index } \\
\text { - Cancer } \\
\text { (CQOLC) } \\
\text { The Medical } \\
\text { Outcomes } \\
\text { Study Short } \\
\text { Form, version } \\
2 \text { (SF-36v2) }\end{array}$ & $\begin{array}{l}\text { From } 191 \text { FCs, } 84 \% \text { were spouses/ } \\
\text { partners, } 90 \% \text { cohabited with the } \\
\text { patient, half were working and } 25 \% \\
\text { had a change in work situation since } \\
\text { the patient's diagnosis. Better FCs' QoL } \\
\text { was associated with better FCs' mental } \\
\text { health (MH) and patient physical well- } \\
\text { being and with not providing care for } \\
\text { other dependents. Worse FCs' MH was } \\
\text { associated with female caregiver sex, } \\
\text { worse patient emotional well-being, } \\
\text { more hours to care and change in the } \\
\text { FCs' work situation. }\end{array}$ \\
\hline
\end{tabular}
FCs' work situation. 
Nur Maziyya: Quality of Life of Family Caregiver of Cancer Patient: A Literature Review

\begin{tabular}{|c|c|c|c|c|c|c|}
\hline $\begin{array}{c}\text { Liliana \& } \\
\text { Ciro, (2012) }\end{array}$ & Colombia & $\begin{array}{c}\text { Descriptive } \\
\text { study }\end{array}$ & $\begin{array}{l}209 \text { FCs of } \\
\text { adults cancer } \\
\text { patients who } \\
\text { attended the } \\
\text { oncology } \\
\text { units in } \\
\text { Medellín, } \\
\text { Colombia }\end{array}$ & $\begin{array}{c}\text { FCs' } \\
\text { Quality of } \\
\text { life }\end{array}$ & $\begin{array}{c}\text { Quality of } \\
\text { life family } \\
\text { version } \\
\text { instrument }\end{array}$ & $\begin{array}{l}\text { FCs' of adult cancer patients have } \\
\text { a negative perception of their QoL. } \\
\text { The most affected dimensions of QoL } \\
\text { were from the physical, psychological, } \\
\text { and social well-being. The spiritual } \\
\text { dimension was the least affected }\end{array}$ \\
\hline $\begin{array}{l}\text { Tzuh, Li, } \\
\text { \& Chen, } \\
\text { (2008) }\end{array}$ & Taiwan & $\begin{array}{l}\text { Prospective, } \\
\text { longitudinal } \\
\text { study }\end{array}$ & $167 \mathrm{FCs}$ & $\begin{array}{l}\text { FCs' } \\
\text { Quality of } \\
\text { life }\end{array}$ & $\begin{array}{l}\text { Caregiver } \\
\text { Quality of } \\
\text { Life Index- } \\
\text { Cancer } \\
\text { (CQOLC) }\end{array}$ & $\begin{array}{l}\text { Family caregivers' (FCs') QoL of } \\
\text { terminally ill cancer patients deteriorate } \\
\text { significantly over time. The deterioration } \\
\text { of a FC's QOL reflects the patient's } \\
\text { increasing distress from symptoms, the } \\
\text { gradual loss of confidence in caregiving } \\
\text { and an increased subjective caregiving } \\
\text { burden on the FC as the patient's death } \\
\text { approaches, and a weaker psychological } \\
\text { resource (i.e., sense of coherence) of the } \\
\text { FC. Taiwanese FCs' QOL deteriorated } \\
\text { significantly as the patient's death } \\
\text { approached }\end{array}$ \\
\hline
\end{tabular}

\section{Discussion}

Family Caregiver's Characteristics

Family caregivers of cancer patients are mostly female, and have a relationship with the patient as a spouses/partner who lives in the same house. This is in accordance with researches that have been done by Sjolander, Rolander, Järhult, Mårtensson, and Ahlstrom (2012); Choi et al. (2015); Rha, Park, Song, Lee, and Lee (2015); Govina et al. (2015); La Mantia, Rossitto and Andaloro (2017); and Wadhwa et al. (2013). The results of a study by Sjolander, Rolander, Järhult, Mårtensson, and Ahlstrom (2012) in Sweden found that $72 \%$ of FCs in cancer patients were female and partners of patients. This is reinforced by research conducted by Choi et al. (2015) in Korea which states that $74.6 \%$ FCs in cancer patients were female and $41.1 \%$ are spouses of patients. Similar results were also shown by research conducted by Rha, Park, Song, Lee, and Lee (2015) in Korea, Govina et al. (2015) in Greece and La Mantia, Rossitto and Andaloro (2017) in Italy which states that more than $65 \%$ of FCs in cancer patients were female and more than $45 \%$ were spouses. While Wadhwa et al. (2013) adds that FCs of cancer patients were spouse $(84 \%)$ who live in a same home $(90 \%)$.

Another characteristic of family caregivers (FCs) of cancer patients were aged over 50 years and patient's parents. This is in accordance with research conducted by Lee et al. (2016); Ito and Tadaka (2017); and Yu et al. (2017). Lee et al. (2016) stated that 73.3\% of FCs in cancer patients in Korea were female with median in aged 50 years. This was reinforced by research conducted by Ito and Tadaka (2017) in Japan which stated that 79.9\% FCs in female cancer patients with an average age of 63.6 years. Another study conducted by Yu et al. (2017) in China stated that $54.7 \%$ of FCs in leukemia patients were female, $44 \%$ were elderly and $36.9 \%$ were spouses of patients.

The results of the above study proves that the spouse is someone who has an important role in the care of cancer patients where the main factor is the love that is owned. This is in accordance with the definition of family caregiver by Guerriere, Zagorski, and Coyte (2010) ie someone who provides care to a brother or a loved one. While family caregivers are mostly female with age above 50 years because cancer patients are mostly male and cancer risk increases based on age increase. This is reinforced by data from the Ministry of Health RI (2015) which states that the prevalence of cancer in men is higher than women and risk factors for cancer increase with age.

\section{Quality of Life Family caregivers}

Family caregivers (FCs) of cancer patients had a decrease in quality of life (QoL), felt burdened in patient caring, depression and psychological distress. This is in accordance 
with research done by some researchers such as Tzuh, Li, and Chen, (2008); Sjolander, Rolander, Järhult, Mårtensson, and Ahlstrom (2012); Kim et al. (2016); and several other researchers. Research conducted by Tzuh, Li, \& Chen, (2008) in Taiwan stated that FCs in cancer patients whose terminal has decreased QoL over time. This is reinforced by the results of research by Song et al. (2011) in Korea and Sjolander, Rolander, Järhult, Mårtensson, and Ahlstrom (2012) in Sweden. Song et al. (2011) stated that the Health related QoL (HRQoL) FCs of terminal cancer patients had significantly decreased compared to FCs treating noncancer patients. In addition, Song et al. Also stated that FCs in cancer patients with terminal conditions experienced depression more often than FCs in addition to cancer. Sjolander, Rolander, Järhult, Mårtensson, and Ahlstrom (2012) corroborated this after taking HRQoL measurements using two different instruments. Both showed that FCs treating cancer patients had low HRQoL.

The decline in quality of life in caregiver family of cancer patients occurs in almost all domains. Several studies have proven this. As a study conducted by Yu et al. (2017) in China that the FCs that treat cancer patients have decreased in the four domains of living life (Physical, psychological, social and environmental). Another study conducted by Liliana and Ciro (2012) shows that FCs of cancer patients have a negative perception of their quality of life with the most affected dimensions are the physical, psychological, and social welfare dimensions. Meanwhile, according to $\mathrm{Lu}$ et al. (2010), the dominant quality of life dominantly decreased is psychological and social welfare.

In contrast to previous research, Rha, Park, Song, Lee, and Lee (2015) stated that most FCs of cancer patients have moderate quality of life and care burden, only one-fourth have low quality of life and high maintenance burden. The results are in contrast to a study conducted by Govina et al. (2015) in Greek which states that FCs of cancer patients have difficulty in providing care and are often depressed. Kim et al. (2016) reinforces these results by conducting studies showing that FCs in lung cancer patients have severe psychological distress.
Factors that affect the quality of life of Family caregivers

Patient factors

Patient factors that affect quality of life include age and patient condition. Younger patients tend to cause a decrease in the quality of life of their FCs. This is in accordance with a study by Choi et al. (2015) in Korea which suggests that younger patients cause a decrease in QoL FCs due to increased care burden. While the condition of patients, which affects the quality of family caregiver is the decline in function, level of independence and stress levels faced by patients. The studies that support this include research conducted by Tzuh, Li, and Chen (2008) in Taiwan and Lu et al. (2010) in China. Tzuh, Li, and Chen, (2008) and Govina et al. (2015) states that the stress experienced by cancer patients and post operated by cancer patients leads to a decline in the quality of life of the caregiver family. While Lu et al. (2010) states that the condition of daily activities of the patient (level of independence) associated with FCs QoL where the more independent the patient it caused higher FCs' QoL.

\section{Family caregivers factors}

Family caregivers factors that affect their quality of life are age, educational and religious level, relationship as a spouse and emotional distress. This is in accordance with research conducted by Lu et al. (2010); Song et al. (2011); and Rha, Park, Song, Lee, and Lee (2015) and several other studies. Lu et al. (2010) states that factors that have a strong relationship with family caregivers' QoL are relationships as a spouse. Song et al. (2011) states that HR-QoL family caregivers of cancer patients have a positive relationship to religion and education levels. Rha, Park, Song, Lee, and Lee (2015) also stated that the factor causing the declining quality of life of family caregivers is the level of education. This is in accordance with the research done by Choi et al. (2015) ie age, marital status, religiousness, relationship with pasian and emotional distress are factors influencing FCs'QoL where emotional disters have the strongest influence (Lee et al., 2016).

Family caregivers with older age, higher education, no religious beliefs, and emotional distress lead to declining quality of life for 
family caregivers (Yu et al., 2017). Sjolander, Rolander, Järhult, Mårtensson, and Ahlstrom (2012) gave more specific explanations that older caregiver families caused a decrease in the domain of physical health, while younger age led to a decline in the mental health domain. Another factor that has a hubuugan with FCs 'QoL is a feeling of depression, FCs' self-efficacy (Ito \& Tadaka, 2017).

\section{Environmental factor}

Environmental factors that affect the quality of life of family caregivers of cancer patients consist of the perceived burden of care, lack of social support and also the level of satisfaction with health services. This is in accordance with the results of research conducted by Song et al. (2011); Rha, Park, Song, Lee, and Lee (2015); Choi et al. (2015); Lee et al. (2016); and Yu et al. (2017).

According to Song et al. (2011) care burden has a negative impact on HR-QoL family caregivers of cancer patients in Korea, the burden is reinforced by the impact of health, financial times and low family support. Rha, Park, Song, Lee, and Lee (2015) also stated that the burden of care has a negative relationship with the quality of life of caregivers family of cancer patients in Korea. The research of Choi et al. (2015) in Korea reinforces that statement that the quality of life of caregiver families of cancer patients is influenced by the burden of care, the level of social support, monthly income. In addition, Choi et al. (2015) adds satisfaction to health care as one of the environmental factors that affect the quality of life of family caregivers. Still in Korea, Lee et al. (2016) mentions that low social support is a factor that affects the low quality of life caregiver family of cancer patients.

A study by Tzuh, Li, and Chen (2008) in Taiwan found that the decline in the quality of family caregiver life was influenced by increased care burden, decreased confidence in care delivery and decreased source of psychological support. Tzuh, Li, and Chen (2008) added that the quality of life of the caregiver family decreased with the time of death of the patient. Research conducted by Yu et al. (2017) in China obtained results that are not much different from previous research that factors that have a strong influence on the overall domain of quality of life caregivers family of cancer patients is social support, followed by family functions that affect 3 domian in the QoL FCs (psychological, social and environmental domains.) In contrast to those results, research conducted by Ito \&and Tadaka (2017) in Japan stated that the presence of subcaregiver and satisfaction towards homecare services is an environmental factor that influences FCs' QoL.

\section{Conclusion}

Family caregiver is a term that refers to someone who cares for a relative or a loved one (Guerriere, Zagorski, \& Coyte, 2010) and tends to be susceptible to decreased quality of life. Research about QoL of FCs of cancer patient have been done in some countries such as Korea, Japan, China, Sweden, Greece, Italy, California, Canada, Colombia, and Taiwan. These studies showed that the primary FCs of cancer patient were spouses and had low QoL. Factors that associated with FCs' QoL such as patients' age and condition, spousal relationship, FCs' religiousness, emotional distress, carigiving burden, lack of social support and satisfaction with care. All of those factors could be categorized in 3 categories, patients factors, family caregivers factors and environmental factors.

\section{References}

American Cancer Society. (2015, December 8). American Cancer Society. Retrieved from American Cancer Society: https://www. cancer.org/cancer/cancer-basics/what-iscancer.html.

Choi, Y.S., Hwang, S.W., Hwang, I.C., Lee, Y.J., Kim, Y.S., Kim, H.M., ..., Koh, S. (2015). Factors associated with quality of life among family caregivers of terminally ill cancer patients. Psycho-Oncology, 224, 217-224. https://doi.org/http://dx.doi. org/10.1002/pon.3904.

Govina, O., Kotronoulas, G., Mystakidou, K., Katsaragakis, S., Vlachou, E., \& Patiraki, E. (2015). Effects of patient and personal 
Nur Maziyya: Quality of Life of Family Caregiver of Cancer Patient: A Literature Review

demographic, clinical and psychosocial characteristics on the burden of family members caring for patients with advanced cancer in Greece. European Journal of Oncology Nursing, 19(1), 81-88. https://doi. org/10.1016/j.ejon.2014.06.009.

Guerriere, Zagorski, \& Coyte. (2010). Care for the family caregiver: A Place to start. NewYork: EmblemHealth.

Ito, E., \& Tadaka, E. (2017). Quality of life among the family caregivers of patients with terminal cancer at home in Japan. Japan Journal of Nursing Science, 14(4), 341-352. https://doi.org/10.1111/jjns.12164.

Kim, J.Y., Sun, V., Raz, D.J., Williams, A.C., Fujinami, R., Reckamp, K., ..., Ferrell, B. (2016). The impact of lung cancer surgery on quality of life trajectories in patients and family caregivers. Lung Cancer, 101, 35-39. https:// doi.org/10.1016/j.lungcan.2016.08.011.

La Mantia, I., Rossitto, F., \& Andaloro, C. (2017). Quality of life in head and neck cancer: Patients' and family caregivers' perceptions. Egyptian Journal of Ear, Nose, Throat and Allied Sciences, 18(3), 247-250. https://doi.org/10.1016/j.ejenta.2017.11.002.

Lee, Y.J., Kim, J.E., Choi, Y.S., Hwang, I.C., Hwang, S.W., Kim, Y.S., ..., Kim, S.J. (2016). Quality of life discordance between terminal cancer patients and family caregivers: A multicenter study. Supportive Care in Cancer, 24(7), 2853-2860. https://doi.org/10.1007/ s00520-016-3108-3.

Liliana, C., \& Ciro, E. (2012). Perception of the quality of life of family caregivers of adults with cancer. Invest Educ Enferm, (3), 320-329.

Lu, L., Pan, B., Sun, W., Cheng, L., Chi, T., \& Wang, L. (2010). Quality of life and related factors among cancer caregivers in China. Psychiatry and Clinical Neurosciences, 64(5), 505-513. https://doi.org/10.1111/ j.1440-1819.2010.02131.x.

Mahendran, R., \& Lim, H.A. (2015). The caregiver quality of life index - Cancer
(CQOLC) in Singapore: A new preliminary factor structure for caregivers of ambulatory patients with cancer, 399-404. https://doi. org/10.1007/s11136-014-0768-7.

National Cancer Institute. (2017). Family caregivers in cancer: Roles and challenges $(P D Q)$. NCBI Bookshelf.

Rha, S.Y., Park, Y., Song, S.K., Lee, C.E., \& Lee, J. (2015). Caregiving burden and the quality of life of family caregivers of cancer patients: The relationship and correlates. European Journal of Oncology Nursing, 19(4), 376-382. https://doi.org/10.1016/j. ejon.2015.01.004.

Sjolander, C., Rolander, B., Järhult, J., Mårtensson, J., \& Ahlstrom, G. (2012). Health-related quality of life in family members of patients with an advanced cancer diagnosis: A one-year prospective study. Health and Quality of Life Outcomes, 10. https://doi.org/10.1186/1477-7525-10-89.

Song, J. I., Shin, D.W., Choi, J.Y., Kang, J., Baik, Y.J., Mo, H., ..., Kim, E.J. (2011). Quality of life and mental health in family caregivers of patients with terminal cancer. Supportive Care in Cancer, 19(10), 15191526. https://doi.org/10.1007/s00520-0100977-8.

Tzuh, S., Li, T. Æ.C., \& Chen, Æ.C.C. (2008). Trajectory and determinants of the quality of life of family caregivers of terminally ill cancer patients in Taiwan. Springer, (17), 387-395. https://doi.org/10.1007/s11136008-9316-7.

Wadhwa, D., Burman, D., Swami, N., Rodin, G., Lo, C., \& Zimmermann, C. (2013). Quality of life and mental health in caregivers of outpatients with advanced cancer. PsychoOncology, 22(2), 403-410. https://doi. org/10.1002/pon.2104.

Weitzner, A., Jacobsen, B., Wagner, H., Friedland, J., Cox, C., Oncology, P., \& Weitzner, P. M. A. (1999). The Caregiver Quality of Life Index - Cancer (CQOLC) scale: Development and validation of an instrument to measure quality of life of the 
Nur Maziyya: Quality of Life of Family Caregiver of Cancer Patient: A Literature Review

family caregiver of patients with cancer, 8(202), 55-63.

WHO. (2018, February 4). World Health Organization. Retrieved from World Cancer Day 2018: http://www.who.int/cancer/en/.

Yu, H., Li, L., Liu, C., Huang, W., Zhou, J., Fu, W., ..., Wu, Q. (2017). Factors associated with the quality of life of family caregivers for leukemia patients in China. Health and Quality of Life Outcomes, 15(1), 1-12. https://doi.org/10.1186/s12955-017-0628-6. 